\title{
Absorção de Anticorpos do Colostro em Bezerros. II. Estudo no Intestino Delgado Distal Rosana Bessi ${ }^{1}$, Patricia Pauletti², Raul Dantas d'Arce ${ }^{3}$, Raul Machado Neto ${ }^{4}$
}

\begin{abstract}
RESUMO - Com o objetivo de estudar a morfologia e determinar a localização da enzima fosfatase ácida na região distal do intestino delgado de bezerros, do nascimento ao fechamento intestinal, foram coletadas amostras de 15 animais machos em três idades: ao nascer sem que houvesse a ingestão de colostro; três horas após a ingestão da primeira refeição de colostro e aos três dias de idade. Observouse, ao nascimento, a presença de um grande vacúolo, que dominava todo o citoplasma das células epiteliais do jejuno distal e íleo. Após a ingestão de colostro, verificou-se o acúmulo de material absorvido nesses vacúolos. Foi detectada a reação de fosfatase ácida nas células absortivas de bezerros recém-nascidos, antes e após a ingestão de colostro. Aos três dias de idade, uma nova população de células geralmente não vacuoladas, com sistema endocítico apical reduzido, foi observada recobrindo as vilosidades intestinais. Portanto, em bezerros a maturação do epitélio absortivo do intestino delgado distal pode iniciar-se com o aumento da atividade enzimática nos vacúolos absortivos, culminando com a rápida substituição das células fetais por células diferenciadas não pinocíticas, o que determinaria o término da transferência de anticorpos maternos.
\end{abstract}

Palavras-chave: íleo, imunoglobulinas, fosfatase ácida

\section{Colostral Antibodies Absorption in Calves. II. Distal Small Intestine Study}

\begin{abstract}
The localization of acid phosphatase at distal small intestine and its morphology were studied from birth to intestinal closure from fifteen male dairy calves aged: unsuckled neonatal, three hours after colostrum ingestion and three days old. At birth, the presence of a large vacuole was found and it expanded all over the epithelial cells cytoplasm at distal jejunum and ileum. For colostrum fed calves, ingested material could be observed in the vacuole. The phosphatase acid reaction was detected in the absorptive cells of suckled and unsuckled newborn calves. Calves aged three days old, a new population of non-vacuolated cells and reduced apical endocytic system were found surrounding the villi. Thus, it's suggested that the absorptive epithelium maturation of distal small intestine can be initiated by increasing the enzymatic activity in the absorptive vacuoles, ending by the substitution of fetal cells, by non-differentiated pinocytic cells and resulting in the cessation of maternal antibody transfer.
\end{abstract}

Key Words: ileum, immunoglobulins, acid phosphatase

\section{Introdução}

A transferência de imunoglobulinas maternas ocorre após o nascimento em ruminantes, com a ingestão da primeira secreção láctea, o colostro. Os anticorpos atravessam a barreira epitelial do intestino delgado, garantindo ao recém-nascido a proteção adequada para as primeiras semanas de vida (Brambell, 1958).

Em bezerros, James et al. (1979) verificaram que a ligação de $\mathrm{I}^{125}$-IgG às membranas do epitélio do intestino delgado aumentou da região proximal para a distal, enquanto Kaup et al. (1996) demonstraram morfologicamente, também em bezerros, que a região médio-caudal do intestino delgado é a principal responsável pela absorção de imunoglobulinas do colostro. No entanto, as células absortivas do íleo de ratos lactentes apresentam elaborado sistema endocítico apical, que consiste de endossomos tubulares e vesiculares, corpos multivesiculares e um grande vacúolo com atividade lisossomal. Esse complexo desenvolve-se rapidamente nos três últimos dias de gestação e está relacionado à digestão intracelular de leite (Wilson et al., 1991). Nesses animais, demonstrou-se que os anticorpos englobados por endocitose não são transportados intactos através da célula, mas encaminhados e degradados nesse grande lisossomo (Abrahamson \& Rodewald, 1981; Hasegawa et al., 1987).

\footnotetext{
${ }^{1}$ Eng. Agrôn., M.Sc., Depto. Produção Animal ESALQ-USP, Av. Pádua Dias, 11, Caixa Postal 9, CEP 13418-900 Piracicaba, SP., Tel (19) 34294260 Fax (19) 3429 4338, E-mail: piracicaba@btconnect.com

2 Eng. Agrôn., M.Sc., Depto. Produção Animal ESALQ-USP, Av. Pádua Dias, 11, Caixa Postal 9, CEP 13418-900 Piracicaba, SP., Tel (19) 34294260 Fax (19) 3429 4338, E-mail: ppaulett@carpa.ciagri.usp.br

3 Eng. Agrôn., Prof. Dr. Depto. de Produção Animal, ESALQ-USP, Av. Pádua Dias, 11, Caixa Postal 9, CEP 13418-900 Piracicaba, SP, Tel (19) 34294260 Fax (19) 34294338.

4 Eng. Agrôn., Prof. Titular, Depto. de Produção Animal, ESALQ-USP, Av. Pádua Dias, 11, Caixa Postal 9, CEP 13418-900 Piracicaba, SP, Tel (19) 34294260 Fax (19) 34294338 E-mail:rmachado@carpa.ciagri.usp.br
} 
A vacuolação do intestino delgado distal é uma característica comum em mamíferos jovens, persistindo por todo o período de aleitamento em ratos e por aproximadamente duas semanas em leitões (Clarke \& Hardy, 1971; Brown \& Moon, 1979; Wilson et al., 1991). Em bezerros, a frequiência desses vacúolos aumenta do jejuno cranial para o íleo e da base para o ápice das vilosidades (Kaup et al., 1996). Células vacuoladas são encontradas em fetos e recém-nascidos, sendo substituídas por epitéliomaduro, nãopinocítico, ao redor dos sete dias de vida (Asari et al., 1987).

Em leitões, detectou-se a atividade de fosfatase ácida nos vacúolos somente após o fechamento intestinal, que ocorre entre 24 e 48 horas de idade (Brown $\&$ Moon, 1979). Comprovou-se em leitões pós-fechamento a acidez dos vacúolos da região distal, que constituiriam um sistema auxiliar de digestão no animal lactente (Baintner, 1994).

Este trabalho teve por objetivo estudar a morfologia e determinar a localização da enzima fosfatase ácida na porção distal do intestino delgado de bezerros, do nascimento ao fechamento intestinal.

\section{Material e Métodos}

Coleta das amostras. Foram utilizados 15 bezerros machos, da raça Holandesa, adquiridos da Fazenda Agrindus S/A. Esses animais foram anestesiados e sacrificados para a coleta de amostras do intestino delgado, em três idades: cinco animais ao nascer sem que houvesse a ingestão de colostro; cinco animais três horas após a ingestão da primeira refeição de colostro, ocorrida na primeira hora de vida, e cinco animais aos três dias de idade, os quais após duas refeições de dois litros de colostro de boa qualidade, provenientes da própria mãe, nas primeiras $24 \mathrm{~h}$ de vida, receberam quatro litros diários de leite integral divididos em duas refeições.

Um segmento de dois centímetros de comprimento foi retirado de duas regiões do intestino delgado, correspondendo ao jejuno distal e íleo. Os tecidos foram fixados por imersão em solução de paraformaldeído $4 \%$ em tampão cacodilato de sódio $0,1 \mathrm{M}$ e sacarose $0,2 \mathrm{M}$ $\mathrm{pH} \mathrm{7,2} \mathrm{por} \mathrm{duas} \mathrm{horas,} \mathrm{lavados} \mathrm{repetidamente} \mathrm{em}$ tampão, para, em seguida, serem retiradas amostras para microscopia óptica e eletrônica.

Microscopia óptica. Amostras de 5x5 mm foram desidratadas em soluções de concentrações crescentes de etanol e embebidas em resina glicol metacrilato (JB4, Polysciences Inc.). Para o estudo da morfologia, secções de $5 \mathrm{~mm}$ de espessura foram coradas em azul de toluidina em tampão fosfato $0,1 \mathrm{M}$ pH 6,8 e pela reação do ácido periódico-Schiff (PAS). Para a localização da atividade da fosfatase ácida, secções adjacentes foram incubadas em meio de Gomori (Bancroft \& Stevens, 1996), completo ou sem a adição do substrato da enzima ( $\beta$-glicerofosfato de sódio), por $90 \mathrm{~min}$ a $37^{\circ} \mathrm{C}$. Amostras de baço de rato, processadas com a mesma resina, foram utilizadas como controle positivo.

Microscopia eletrônica de varredura. Segmentos de 5x5 mm foram pós-fixados em solução de tetróxido de ósmio $1 \%$ em tampão cacodilato de sódio $0,1 \mathrm{M} \mathrm{pH} 7,2$ e desidratados em soluções de concentrações crescentes de acetona. Após a secagem ao ponto crítico, os espécimes foram recobertos com ouro e examinados ao microscópio LEO 435 VP.

Microscopia eletrônica de transmissão. Amostras de $1 \times 2 \mathrm{~mm}$ foram pós-fixadas em solução de tetróxido de ósmio $1 \%$ em tampão cacodilato de sódio $0,1 \mathrm{M} \mathrm{pH} 7,2$, desidratadas em soluções de concentrações crescentes de acetona e embebidas em resina Spurr. Secções prateadas foram coletadas em telas de cobre e contrastadas em acetato de uranila e citrato de chumbo. Para imunocitoquímica, amostras de $1 \times 2 \mathrm{~mm}$ foram desidratadas em soluções de concentrações crescentes de etanol e embebidas em resina LR White.

Imunomarcação. Secções douradas foram coletadas em telas de níquel e incubadas sucessivamente em leite desnatado $1 \%$, anti-IgG bovino produzido em coelhos (Sigma Chemical Co.) e proteína A conjugada a ouro (Sigma Chemical Co.), com partículas de $20 \mathrm{~nm}$. A contrastação foi feita em acetato de uranila e citrato de chumbo. As amostras foram observadas ao microscópio Zeiss EM 900.

\section{Resultados e Discussão}

O jejuno distal e o íleo apresentaram características semelhantes e serão descritos em conjunto. Nessas regiões do intestino delgado, observaram-se placas de Peyer na submucosa, estruturas que alojam o tecido linfóide do trato intestinal. Do tecido linfóide partiram expansões recobertas por tecido epitelial prismático simples, formando pseudovilosidades.

Nos recém-nascidos que não receberam colostro observaram-se, ao microscópio óptico, células epiteliais com núcleos muito deslocados para a base e a presença de vacúolos que dominavam todo o

R. Bras. Zootec., v.31, n.6, p.2325-2331, 2002 
citoplasma (Figura 1). A altura das células e o tamanho dos vacúolos diminuíram em direção à base das vilosidades (Figura 2). Os vacúolos podiam se apresentar sem coloração ou preenchidos por material PAS-positivo, ocupando 2/3 superior das vilosidades e o número de células caliciformes foi maior na base das vilosidades. Nos bezerros que mamaram colostro, os vacúolos apicais estavam preenchidos por glóbulos de material absorvido, tanto na região apical quanto na basal da vilosidade (Figuras 3 e 4). Já aos três dias de idade, as células vacuoladas foram substituídas por células com núcleos basais, geralmente não vacuoladas (Figuras 5 e 6 ).

As vilosidades do jejuno distal e íleo, examinadas ao microscópio eletrônico de varredura, apresentaram-se em forma de língua, com tamanho uniforme e sem variação entre as diferentes idades avaliadas (Figura 7).

Quanto à ultra-estrutura observaram-se grandes vacúolos no citoplasma apical, preenchidos uniformemente por material flocular, nos recém-nascidos que não receberam colostro. As microvilosidades foram bem definidas e o sistema endocítico apical apresentou túbulos estreitos ou dilatados, com invaginações da membrana plasmática apical (Figura 8). Núcleos e organelas foram localizados no citoplasma periférico. Nos bezerros que receberam colostro, material elétron-denso foi observado preenchendo os vacúolos apicais (Figura 9) e, por localização com proteína A-ouro, comprovou-se a presença de IgG (Figura 11). Aos três dias de idade, o glicocálice era bem evidente e os enterócitos apresentaram microvilosidades menores e pequenos vacúolos ou corpos multivesiculares dispersos pelo citoplasma (Figura 10). No citoplasma apical, observaram-se numerosas mitocôndrias, pequenos túbulos formados pela invaginação da membrana plasmática apical e vesículas elétron-densas.

Para a reação da fosfatase ácida, um dos bezerros que não receberam colostro apresentou reação nos vacúolos do jejuno distal e dois nos vacúolos do íleo (Figura 12). Nos animais que receberam colostro, dois foram positivos nos vacúolos apicais do jejuno distal e íleo (Figura 13). A marcação nos vacúolos restringiu-se às membranas. Não foi detectada reaão ao três dias de idade, tanto no citoplasma quanto na bordadura em escova.

Amostras do intestino delgado distal foram examinadas ao microscópio eletrônico de varredura, não tendo sido observada variação na forma das vilosidades, em bezerros nas três condições avaliadas nesse trabalho. O formato em língua, que também foi verificado por Asari et al. (1987) em bezerros de cinco semanas de idade, sugere que, mesmo com as mudanças morfológicas observadas em bezerros após o nascimento, essa forma característica se mantém em animais mais velhos.

Nos recém-nascidos, a presença de vacuolação em todo o citoplasma foi a característica marcante das células epiteliais do intestino delgado distal, quando observadas ao microscópio óptico. Observação semelhante foi feita por Kaup et al. (1996), em bezerros recém-nascidos e às 24 horas de vida, e por Mebus et al. (1975), em bezerro aos dois dias de idade. Enquanto em ratos lactentes, o sistema endocítico apical degrada proteínas absorvidas, em bezerros, a presença de grandes vacúolos apicais foi associada a maior capacidade de transferência de anticorpos maternos (Kaup et al., 1996). James et al. (1979) sugeriram que, com o aumento da exposição do epitélio intestinal às imunoglobulinas, a região distal do intestino delgado teria maior capacidade de retenção de proteína. Essas células vacuoladas acumulariam proteínas neste rápido período de intensa internalização.

Wilson et al. (1991) demonstraram que a diferenciação do lissossomo apical das células do íleo de ratos somente ocorre no primeiro dia pós-natal, permanecendo por todo o período de aleitamento. A detecção da enzima fosfatase ácida foi utilizada nesse trabalho para demonstrar a atividade de enzimas hidrolíticas nos enterócitos de bezerros. Foram encontradas evidências do desenvolvimento de digestão intracelular nos vacúolos apicais, com a detecção de reação positiva em recém-nascidos antes e após a ingestão de colostro. Kaup et al. (1996) sugeriram que o jejuno caudal e o íleo de bezerros apresentavam a maior quantidade de material absorvido, pelo maior grau de vacuolação verificado nas células dessas regiões. No entanto, ainda não havia sido descrita reação de enzimas lisosômicas no intestino delgado distal de bezerros recém-nascidos, antes do presente estudo. Da mesma maneira que nas células do intestino delgado proximal e médio, não está claro se a reação observada poderia causar degradação significativa das imunoglobulinas do colostro. Entretanto, não se pode descartar a hipótese do estabelecimento pós-natal de degradação enzimática das proteínas absorvidas, como já foi descrito em ratos, e que a transferência dessas proteínas não seria necessaria-

R. Bras. Zootec., v.31, n.6, p.2325-2331, 2002 


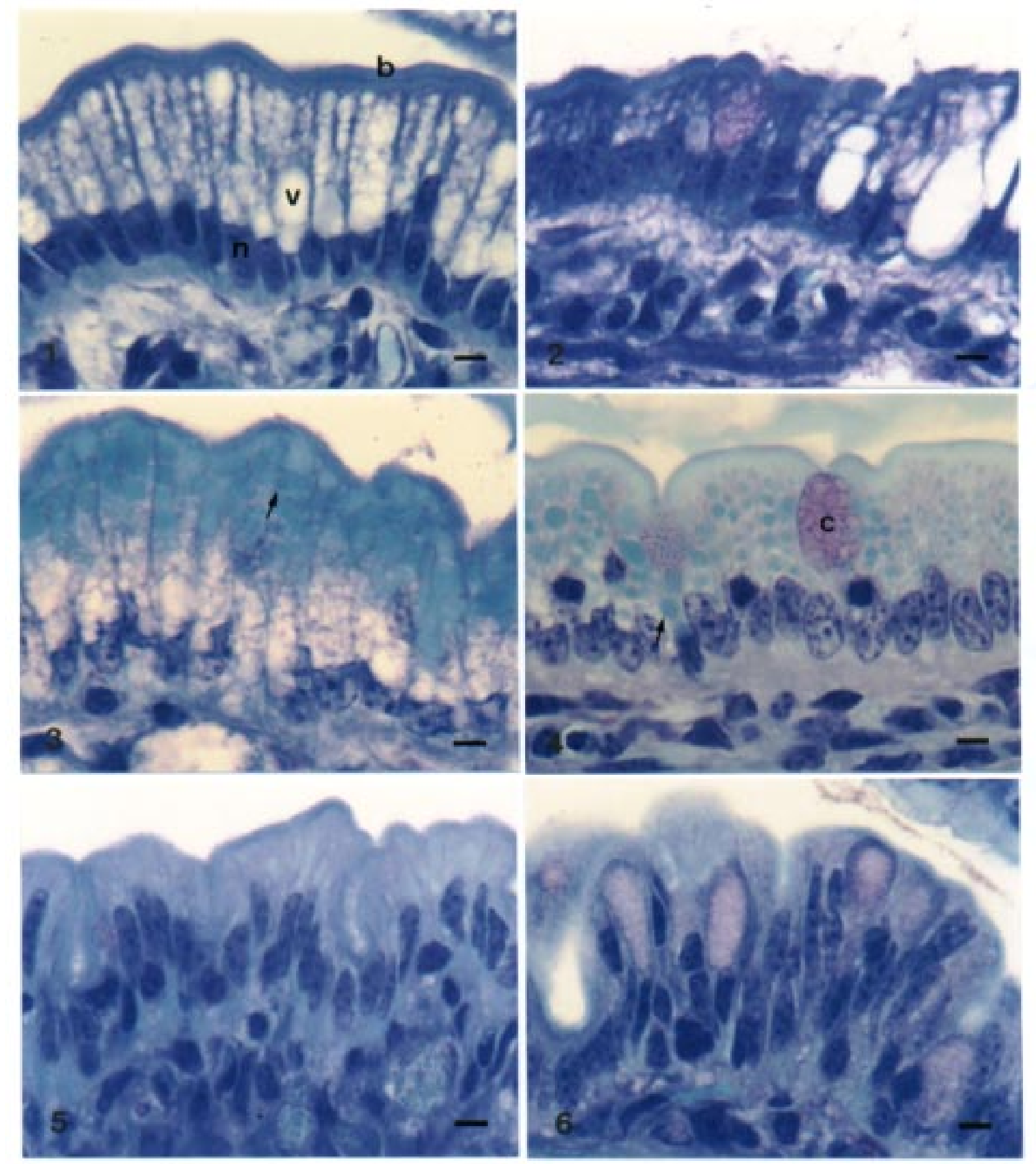

Figura 1 - Epitélio do íleo de bezerro recém-nascido sem a ingestão de colostro.

Figure 1 - lleal epithelium of unsuckled neonatal calf.

Figura 2 - Epitélio da base da vilosidade do íleo de bezerro recém-nascido sem a ingestão de colostro.

Figure 2 - Basal villus epithelium of unsuckled neonatal calf.

Figura 3 - Epitélio do íleo de bezerro recém-nascido após a ingestão de colostro.

Figure 3 - Ileal epithelium of a colostrum fed neonatal calf.

Figura 4 - Epitélio da base da vilosidade do íleo de bezerro recém-nascido após a ingestão de colostro.

Figure 4 - Basal villus epithelium of colostrum fed neonatal calf.

Figura 5 - Epitélio do íleo de bezerro aos três dias de idade.

Figure 5 - Ileal epithelium of three-day-old calf.

Figura 6 - Epitélio da base da vilosidade do íleo de bezerro aos três dias de idade.

Figure 6 - Basal villus epithelium of three-day-old calf.

Legenda: v: vacúolo; $\mathrm{n}$ : núcleo; b: bordadura em escova; c: célula caliciforme; seta: material absorvido. Barra = $5 \mathrm{~mm}$. Legend: $\quad$ : vacuole; $n$ : nucleus; b: brush border; c: goblet cell; arrow: absorbed material. Bar $=5 \mathrm{~mm}$.

\section{R. Bras. Zootec., v.31, n.6, p.2325-2331, 2002}




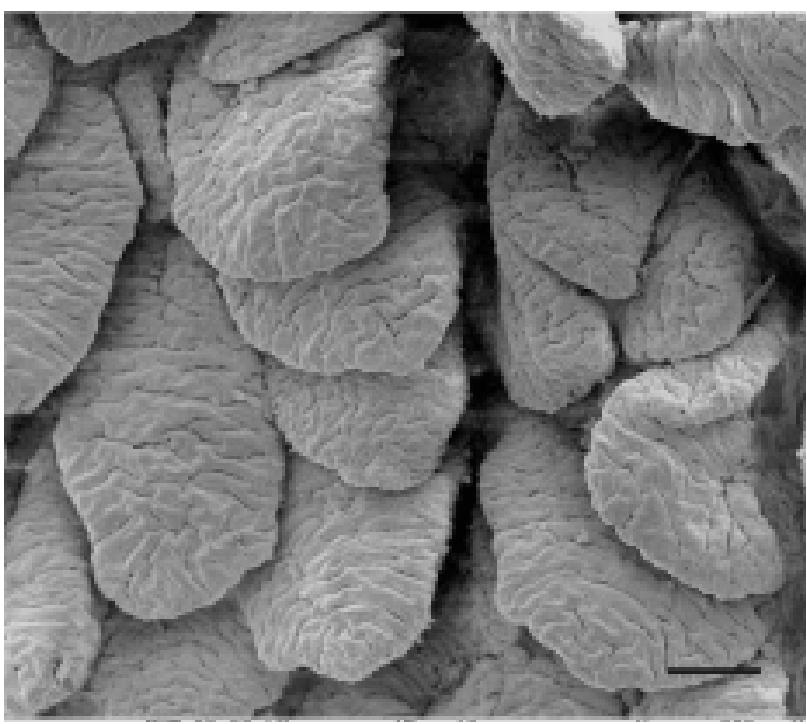

Figura 7 - Vilosidades do íleo de bezerro. Barra $=100 \mathrm{~mm}$. Figure 7 - lleal villi of a neonatal calf. Bar $=100 \mathrm{~mm}$.

mente proporcional ao acúmulo.

Asari et al. (1987) verificaram que as células vacuoladas que recobrem as vilosidades do íleo no feto e no recém-nascido bovinos foram substituídas por um epitélio maduro, não pinocítico, que emerge das criptas, por volta do sétimo dia de vida. No entanto, em cordeiros, Smeaton \& Simpson-Morgan (1985) observaram o aumento na atividade mitótica nas criptas intestinais e a proliferação de um tipo diferenciado de célula epitelial que determinaram a renovação celular em dois ou três dias após o nascimento. Observou-se, nos aos três dias de idade, rápida substituição do epitélio por células mais maduras, semelhantes às observadas por Ladsverk (1979), em bezerros com três semanas de idade. Desse

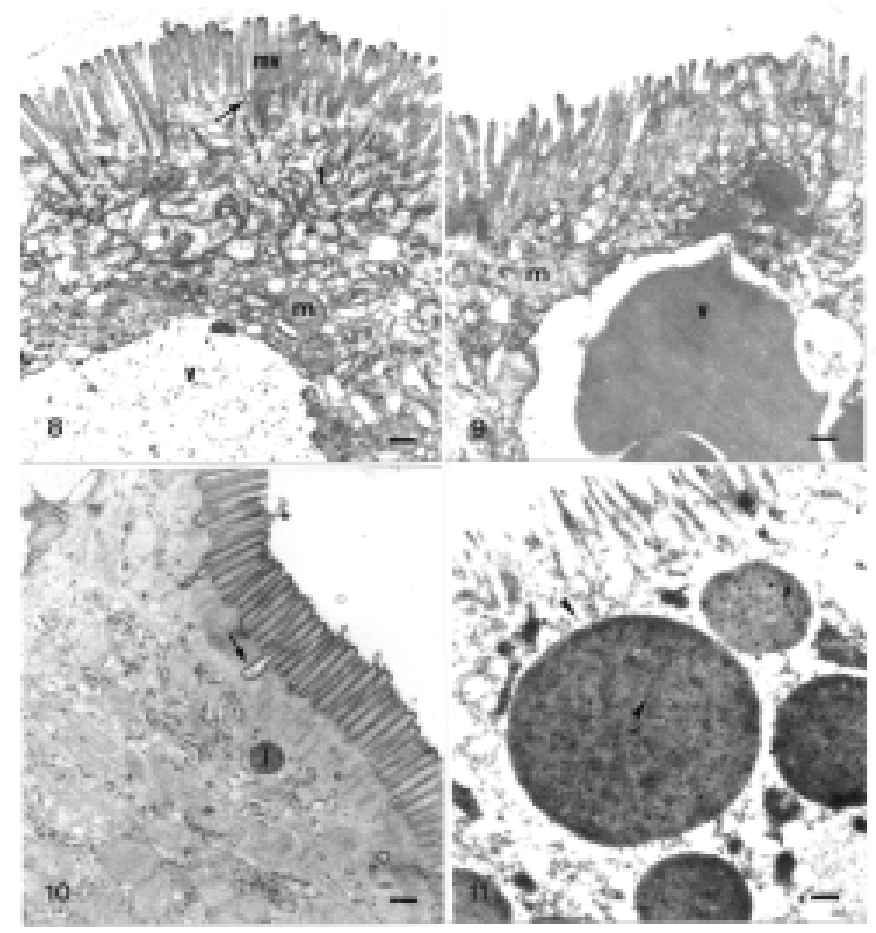

Figura 8 - Citoplasma apical de enterócito do íleo de bezerro recém-nascido sem a ingestão de colostro. Bar$\mathrm{ra}=0,36 \mathrm{~mm}$.

Figure 8 - Apical end of ileal enterocyte of unsuckled neonatal calf. Bar $=0.36 \mathrm{~mm}$.

Figura 9 - Citoplasma apical de enterócito do íleo de bezerro após a ingestão de colostro. Barra $=0,36 \mathrm{~mm}$.

Figure 9 - Apical end of ileal enterocyte of a colostrum fed calf. Bar $=0.36 \mathrm{~mm}$

Figura 10 - Citoplasma apical de enterócito do íleo de bezerro aos três dias de idade. Barra $=0,36 \mathrm{~mm}$.

Figure 10 - Apical end of ileal enterocyte of a three-day-old calf. $B a r=0.36 \mathrm{~mm}$.

Figura 11 - Localização de IgG no citoplasma apical de enterócito de íleo de bezerro. Barra $=0,36 \mathrm{~mm}$.

Figure 11 - lgG localization in the apical end of ileal enterocyte of calf. Bar $=0.36 \mathrm{~mm}$.

Legenda: v: vacúolo; ponta de seta: partículas de ouro; m: mitocôndria; seta: invaginação da membrana apical. Legend: $\quad v$ : vacuole; arrowhead: gold particle; $m$ : mitochondria; arrow: membrane invagination. 


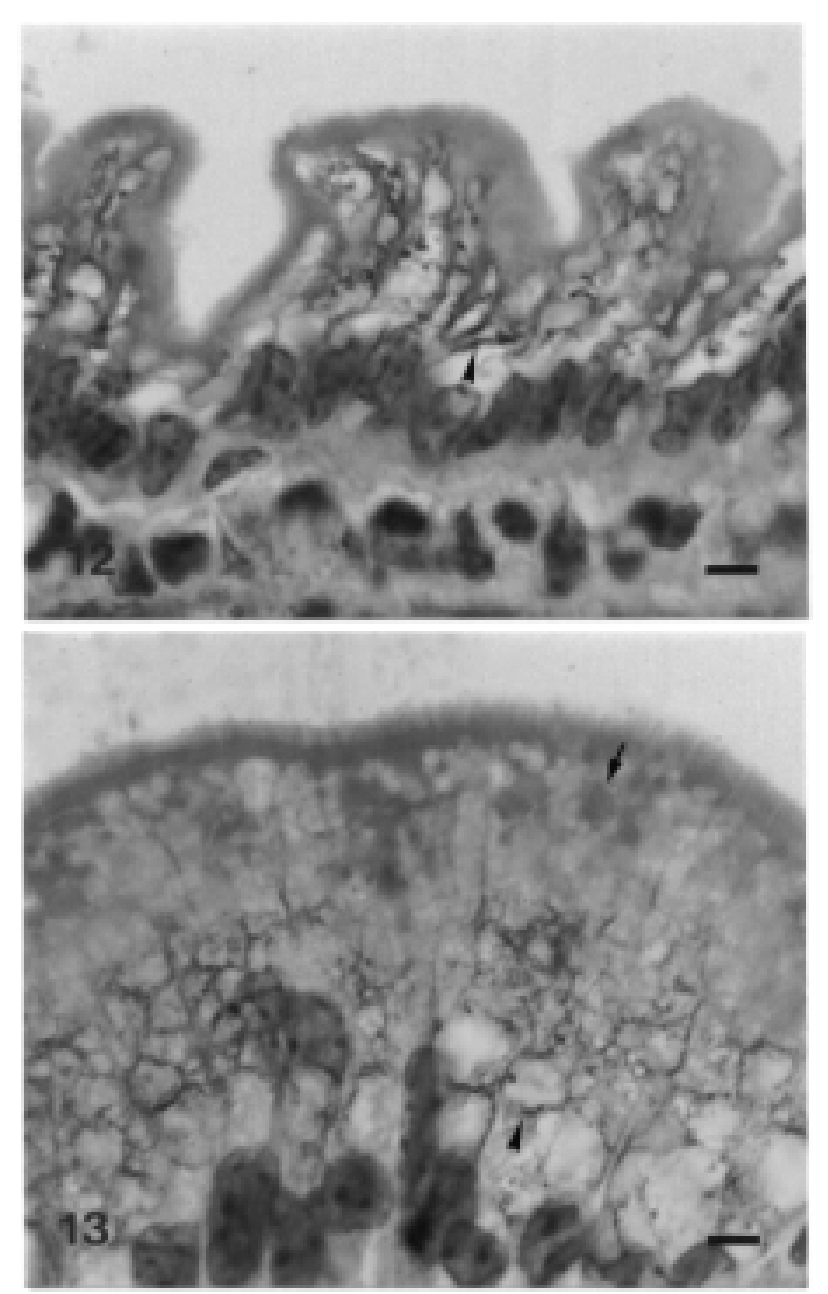

Figura 12 - Reação de fosfatase ácida no epitélio do íleo de bezerro recém-nascido sem a ingestão de colostro.

Figure 12 - Acid phosphatase reaction in the ileal epithelium of unsuckled neonatal calf.

Figura 13 - Reação de fosfatase ácida no epitélio do íleo de bezerro recém-nascido após a ingestão de colostro.

Figure 13 - Acid phosphatase reaction in the ileal epithelium of colostrum fed calf.

Legenda: ponta de seta: reação de fosfatase ácida; seta: vacúolo preenchido por material absorvido. Barra $=5 \mathrm{~mm}$. Legend: arrowhead: acid phosphatase reaction; arrow: absorptive vacuole. $B a r=5 \mathrm{~mm}$. modo, o estudo morfológico apresentado nesse trabalho concorda com a hipótese de rápida renovação celular no intestino delgado, uma vez que, em bezerros aos três dias de vida, o epitélio diferenciado estava presente, com sistema endocítico reduzido e diminuição drástica dos vacúolos.

Em leitões, Clarke \& Hardy (1971) sugeriram que no íleo ocorreria o fechamento intestinal progressivo: o enterócito deixaria inicialmente de transferir proteínas para o espaço intercelular, sendo formados vacúolos digestivos que perdurariam por até duas semanas de idade e, posteriormente, deixaria de internalizá-las pela membrana apical. No presente estudo, diferentemente do que foi observado em leitões, a morfologia do intestino delgado distal de bezerros aos três dias de idade indica que o fechamento ocorreria mais rapidamente nesses animais.

\section{Conclusões}

A maturação do epitélio absortivo do intestino delgado distal de bezerros pode iniciar-se com o aumento da atividade enzimática nos vacúolos absortivos, culminando com a rápida substituição das células fetais por células diferenciadas não pinocíticas, o que determinaria o término da transferência de anticorpos maternos.

\section{Literatura Citada}

ABRAHAMSON, D.R.; RODEWALD, R. Evidence for the sorting of endocytic vesicle contents during the receptormediated transport of $\mathrm{IgG}$ across the newborn rat intestine. Journal of Cell Biology, v.91, n.1, p.270-280, 1981.

ASARI, M.; KAWAGUCHI, N.; WAKUI, S. et al. Development of the bovine ileal mucosa. Acta Anatomica, v.129, n.4, p.315-324, 1987.

BAINTNER, K. Demonstration of acidity intestinal vacuoles of the suckling rat and pig. Journal of Histochemistry and Cytochemistry, v.42, n.2, p.231-238, 1994.

BANCROFT, J.D.; STEVENS, A. Enzyme histochemistry: theory and practice of histological techniques. New York: Churchill Livingstone, 1996. 766p. 
BRAMBELL, F.W.R. The passive immunity of the young mammal. Biological Reviews, v.33, n.4, p.488-531, 1958.

BROWN, H.H.; MOON, H.W. Localization and activities of lysosomal enzymes in jejunal and ileal epithelial cells of the young pig. American Journal of Veterinary Research, v.40, n.11, p.1573-1577, 1979.

CLARKE, R.M.; HARDY, R.N. Histological changes in the small intestine of the young pig and their relation to macromolecular uptake. Journal of Anatomy, v.108, n.1, p.63-77, 1971.

HASEGAWA, H.; NAKAMURA, A.; WATANABE, K. et al. Intestinal uptake of IgG in suckling rats. Gastroenterology, v.92, n.1, p.186-191, 1987.

JAMES, R.E.; POLAN, C.E.; McGILLIARD, M.L. Distributional uptake of g-globulin in small intestine of neonatal calves. Journal of Dairy Science, v.62, n.9, p.1415-1419, 1979.

KAUP, F.J.; DORMMER, W.; JOCHIMS, K. et al. Ultrastructure of pre- and postcolostral enterocytes of the newborn calf. Anatomia Histologia Embryologia, v.25, n.4, p.249-255, 1996.

LANDSVERK, T. The gastrointestinal mucosa in young milkfed calves. Acta Veterinaria Scandinavica, v.20, n.4, p.572-582, 1979
MEBUS, C.A.; NEWMAN, L.E.; STAIR, E.L. Scanning electron, light, and transmission electron microscopy of intestine of gnotobiotic calf. American Journal of Veterinary Research, v.36, n.7, p.985-993, 1975.

SMEATON, T.C.; SIMPSON-MORGAN, M.W. Epithelial cell renewal and antibody transfer in the intestine of the foetal and neonatal lamb. Australian Journal of Experimental Biology and Medical Science, v.63, n.1, p.41-51, 1985.

WILSON, J.M.; WHITNEY, J.A.; NEUTRA, M.R. Biogenesis of the apical endosome-lysosome complex during differentiation of absorptive epithelial cells in rat ileum. Journal of Cell Science, v.100, Part 1, p.133-143, 1991.

Recebido em: 14/12/01

Aceito em: 26/07/02 